\title{
The effect of different layered materials on the tribological properties of PTFE composites
}

\author{
Song LI ${ }^{1,2}$, Chunjian DUAN ${ }^{1,2}$, Xiao $\mathbf{L I}^{1,2}$, Mingchao SHAO ${ }^{1,2}$, Chunhui $\mathbf{Q U}^{1,2}$, Di ZHANG ${ }^{1}$, Qihua WANG ${ }^{1, *}$, \\ Tingmei WANG ${ }^{1}$, Xinrui ZHANG ${ }^{1, *}$ \\ ${ }^{1}$ State Key Laboratory of Solid Lubrication, Lanzhou Institute of Chemical Physics, Chinese Academy of Sciences, Lanzhou 730000, China \\ ${ }^{2}$ University of Chinese Academy of Sciences, Beijing 100049, China
}

Received: 26 October 2018 / Revised: 19 December 2018 / Accepted: 09 January 2019

(C) The author(s) 2019.

\begin{abstract}
Two-dimensional (2D) lamellar materials have unique molecular structures and mechanical properties, among which molybdenum disulfide $\left(\mathrm{MoS}_{2}\right)$ and graphitic carbon nitride $\left(\mathrm{g}-\mathrm{C}_{3} \mathrm{~N}_{4}\right)$ with different interaction forces served as reinforcing phase for polytetrafluoroethylene (PTFE) composites in the present study. Thermal stability, tribological and thermomechanical properties of composites were comprehensively investigated. It was demonstrated that $\mathrm{g}-\mathrm{C}_{3} \mathrm{~N}_{4}$ improved elastic deformation resistance and thermal degradation characteristics. The addition of $\mathrm{g}-\mathrm{C}_{3} \mathrm{~N}_{4}$ significantly enhanced anti-wear performance under different loads and speeds. The results indicated that PTFE composites reinforced by $\mathrm{g}-\mathrm{C}_{3} \mathrm{~N}_{4}$ were provided with better properties because the bonding strength of $\mathrm{g}-\mathrm{C}_{3} \mathrm{~N}_{4}$ derived from hydrogen bonds (H-bonds) was stronger than that of $\mathrm{MoS}_{2}$ with van der Waals force. Consequently, $g-\mathrm{C}_{3} \mathrm{~N}_{4}$ exhibited better thermomechanical and tribological properties. The result of this work is expected to provide a new kind of functional filler for enhancing the tribological properties of polymer composites.
\end{abstract}

Keywords: graphitic carbon nitride; lamellar materials; hydrogen bonds; wear resistance

\section{Introduction}

Polymers and their composites are extensively used as tribo-engineering materials. The excellent physical and chemical characteristics of polymer-based composites make them a promising class of important tribomaterials because of their self-lubricating performance, chemical stability, superior process ability as well as cost-effectiveness [1-3].

Polytetrafluoroethylene (PTFE) polymer exhibits extraordinary characteristics such as high thermal resistance, ease of fabrication, outstanding chemical inertness, low friction coefficient, etc. Therefore, considerable efforts have been made to extend its applications in industry and academic research where sealing and lubricating issues are of special importance. However, the poor mechanical properties and high wear rate of PTFE have limited its application in the abovementioned fields [4-6]. To reduce the wear rate and exploit the advantages of PTFE, researchers have found that load-carrying capability and wear resistance can be improved by filling the PTFE matrix with various fillers such as organic and inorganic fibers $[7,8]$, and nano- and microscaled particles $[9,10]$. For example, Burris and Sawyer reported improvement in anti-wear properties by up to four-orders of magnitude by incorporating nano- $\mathrm{Al}_{2} \mathrm{O}_{3}$ into PTFE [11]. The modification of tribological performance of PTFE composites was found to be closely related to the improvement in hardness, compressive strength, stiffness, and creep resistance [12-14].

Driven by the potential applications of PTFE composites in the automotive and aerospace industries, much attention has been paid to the enhancement of

* Corresponding authors: Qihua WANG, E-mail: wangqh@licp.cas.cn; Xinrui ZHANG, E-mail: xruiz@licp.cas.cn 
the anti-wear performance of PTFE composites. Fan et al. [15] showed that potassium titanate whiskers were effective in increasing the wear resistance of PTFE composites. Song et al. [16] revealed the synergistic effect of molybdenum disulfide $\left(\mathrm{MoS}_{2}\right)$ and glass fiber in enhancing wear resistance. When tribological stability is considered, PTFE composites were found to be superior to phenol formaldehyde resins and poly-p-hydroxybenzoic acid composites in vacuum condition [17].

Over the past several years, two-dimensional (2D) materials, e.g., $\mathrm{WS}_{2}, \alpha-\mathrm{ZrP}, \mathrm{MoS}_{2}$, graphite, etc., have been recognized as excellent candidates for tribological modification of polymers owing to their unique molecular structures [18-20]. Among 2D materials, graphite-like carbon nitride $\left(\mathrm{g}-\mathrm{C}_{3} \mathrm{~N}_{4}\right.$ ) (Fig. 1(a)) is of special interest because of the strong hydrogen bonds (H-bonds) between strands of polymeric melon units and $\mathrm{NH} / \mathrm{NH}_{2}$ groups (Fig. 1(b)), which contribute to its high mechanical properties [21-24].

Nevertheless, reports on the tribological properties of composites reinforced by $\mathrm{g}-\mathrm{C}_{3} \mathrm{~N}_{4}$ are very rare. In addition, few researchers have explored the thermal stability and tribological and thermomechanical properties of composites via the incorporation of

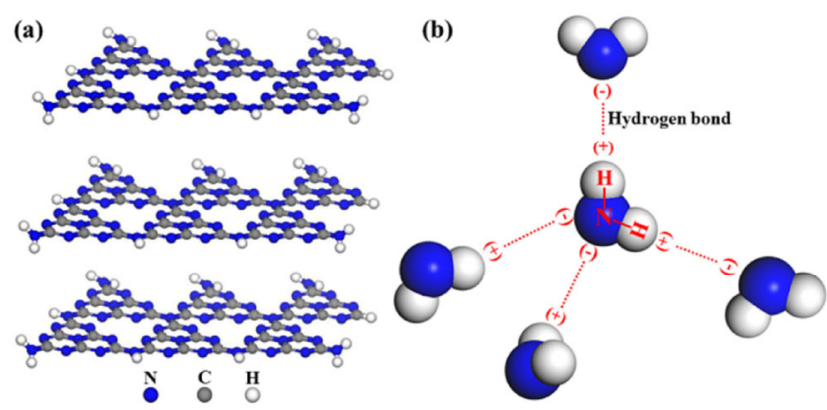

Fig. 1 Schematic illustration of (a) $g-\mathrm{C}_{3} \mathrm{~N}_{4}$ and (b) interlayer H-bonds for $\mathrm{g}-\mathrm{C}_{3} \mathrm{~N}_{4}$. different lamellar materials with different interaction forces between layers. In the present work, g- $\mathrm{C}_{3} \mathrm{~N}_{4}$ is successfully synthesized, and its structure and morphology are inspected. Moreover, the addition of $\mathrm{MoS}_{2}$ and $\mathrm{g}-\mathrm{C}_{3} \mathrm{~N}_{4}$ to worn surfaces and tribofilms of PTFE composites is also analyzed systematically. The experimental results show that sheet-like materials with H-bonds play a major role in enhancing thermal stability and tribological and thermomechanical performance.

\section{Experiment}

\subsection{Materials and preparation}

The formulations of PTFE composites are listed in Table 1 and obtained with our previous method [25-28].

Two different types of layered materials $\left(\mathrm{MoS}_{2}\right.$, g- $\mathrm{C}_{3} \mathrm{~N}_{4}$ ) were used as functional fillers to reinforce PTFE composites. Their morphologies are shown in Fig. 2. $\mathrm{MoS}_{2}$ micropowders with an average diameter of $20 \mu \mathrm{m}$ and purity of $99.9 \%$ were purchased from Beijing DK Nano technology Co. Ltd. The yellowish g- $\mathrm{C}_{3} \mathrm{~N}_{4}$ powders were synthesized by directly heating melamine $\left(\mathrm{C}_{3} \mathrm{~N}_{6} \mathrm{H}_{6}\right.$, Tianjin Kemiou Chemical Regant Co., Ltd.) at $550{ }^{\circ} \mathrm{C}$ for $4 \mathrm{~h}$ following previous works $[27,29]$; the sizes are shown in Fig. 3. Detailed information on the other compositions is summarized in Table 2. The fillers were added and mixed in a shredding machine for $3 \mathrm{~min}$. Next, the composites were fabricated by cold press (40 MPa, $20 \mathrm{~min})$ and then sintered in an oven $\left(375^{\circ} \mathrm{C}, 120 \mathrm{~min}\right)$.

\subsection{Tribological tests}

Tribological tests were conducted under ambient

Table 1 The formulations and related properties of PTFE composites.

\begin{tabular}{|c|c|c|c|c|c|c|c|c|c|}
\hline \multirow{2}{*}{ Composites } & \multirow{2}{*}{$\begin{array}{l}\text { Density } \\
\left(\mathrm{g} / \mathrm{cm}^{3}\right)\end{array}$} & \multirow{2}{*}{$\begin{array}{l}\text { Hardness } \\
\text { (Shore D) }\end{array}$} & \multicolumn{7}{|c|}{ Composition (wt.\%) } \\
\hline & & & PTFE & PTWs & Nano-SiO ${ }_{2}$ & $\mathrm{Cu}$ & Aramid pulp & $\mathrm{MoS}_{2}$ & $\mathrm{~g}-\mathrm{C}_{3} \mathrm{~N}_{4}$ \\
\hline $\mathrm{FM}^{\mathrm{a}}$ & 2.31 & 59.2 & 88 & 6.5 & 2.2 & 1.1 & 2.2 & 0 & 0 \\
\hline $\mathrm{FM} 2^{\mathrm{b}}$ & 2.34 & 60.3 & 78 & 6.5 & 2.2 & 1.1 & 2.2 & 10 & 0 \\
\hline $\mathrm{FM}^{\mathrm{c}}$ & 2.11 & 61.2 & 78 & 6.5 & 2.2 & 1.1 & 2.2 & 0 & 10 \\
\hline
\end{tabular}

${ }^{\mathrm{a}}$ PTFE composites without addition of $\mathrm{MoS}_{2}$ and $\mathrm{g}-\mathrm{C}_{3} \mathrm{~N}_{4}$ are abbreviated as FM1.

${ }^{\mathrm{b}}$ PTFE composites with addition of $\mathrm{MoS}_{2}$ are abbreviated as FM2.

${ }^{\mathrm{c}}$ PTFE composites with addition of $\mathrm{g}-\mathrm{C}_{3} \mathrm{~N}_{4}$ are abbreviated as FM3. 


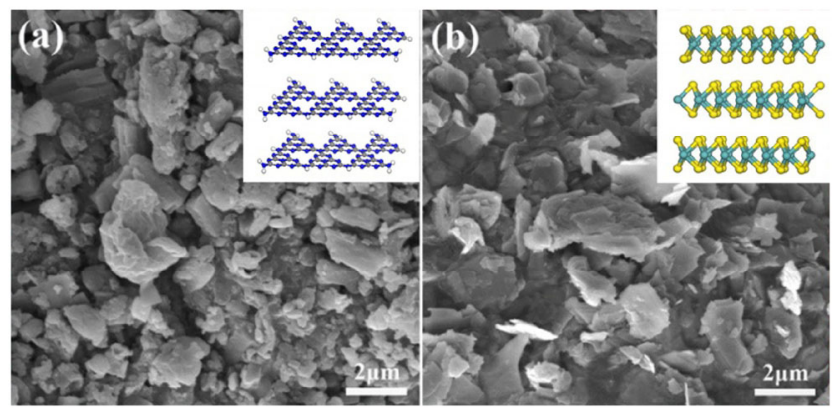

Fig. 2 SEM images of particles: (a) $g-\mathrm{C}_{3} \mathrm{~N}_{4}$ and (b) $\mathrm{MoS}_{2}$ (inset images represent corresponding schematic drawings of the crystalline structures of $\mathrm{g}-\mathrm{C}_{3} \mathrm{~N}_{4}$ and $\mathrm{MoS}_{2}$ ).

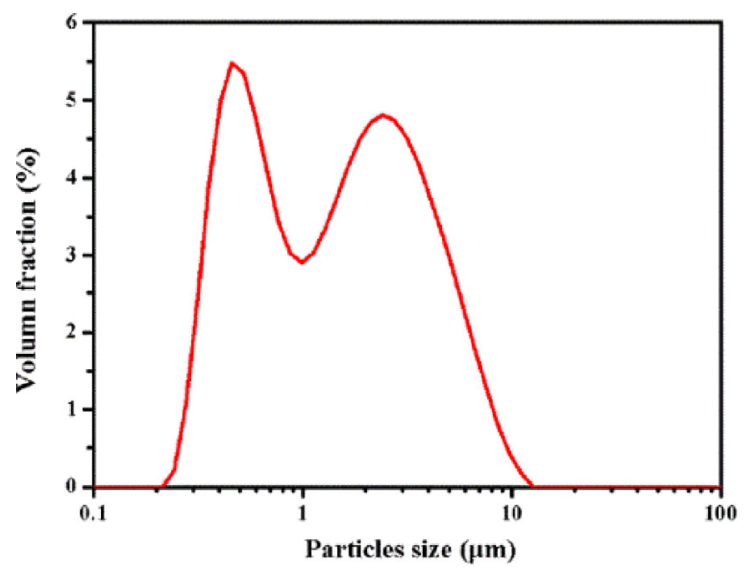

Fig. 3 The particles size range of the $g-\mathrm{C}_{3} \mathrm{~N}_{4}$.

Table 2 The detailed information of raw materials.

\begin{tabular}{ccc}
\hline $\begin{array}{c}\text { Raw } \\
\text { materials }\end{array}$ & Size & Supplier \\
\hline PTFE & $75 \mu \mathrm{m}$ & $\begin{array}{c}\text { Daikin Fluorochemicals } \\
\text { Co., Ltd. }\end{array}$ \\
PTWs & $0.5-2.5 \mu \mathrm{m}$ & $\begin{array}{c}\text { Shanghai Whiskers Composite } \\
\text { Material Co., Ltd. }\end{array}$ \\
Nano-SiO 2 & $20 \mathrm{~nm}$ & $\begin{array}{c}\text { Beijing DK Nano technology } \\
\text { Co., Ltd. }\end{array}$ \\
Aramid pulp & $800-1350 \mu \mathrm{m}$ & $\begin{array}{c}\text { Teijin aramid Trade Co. Ltd. } \\
\text { Beijing DK Nano technology } \\
\text { Cu }\end{array}$ \\
\end{tabular}

conditions on a tribometer (CSM, Switzerland) with ball-on-disc configuration, which is schematically illustrated in Fig. 4. During the tests, the counterbody stainless steel ball (GCr15, GB/T 18254-2002, $3 \mathrm{~mm}$ diameters) was static while the polymer composite disc rotated against the ball under normal load. The friction tests lasted $120 \mathrm{~min}$ at different sliding speeds $(0.04,0.08$, and $0.12 \mathrm{~m} / \mathrm{s})$ and normal loads $(1,3$, and $5 \mathrm{~N})$, respectively. Prior to the tests, the surfaces of the

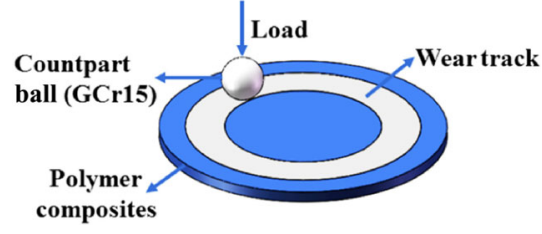

Fig. 4 Schematic illustration of ball-on-disc wear test.

specimens were finished by polishing to a roughness of approximately $0.2-0.3 \mu \mathrm{m}$. The steel balls were cleaned with alcohol-dipped cotton to remove surface humidity. Thereafter, each friction measurement was repeated at least three times to evaluate the friction coefficient and specific wear rate $(W)$. The friction coefficient from the steady friction stage at last one hour was dynamically recorded, and $W$ was calculated by the following relationship:

$$
W=\Delta V / P L\left(\mathrm{~mm}^{3} /(\mathrm{N} \cdot \mathrm{m})\right)
$$

where $P$ and $L$ are the applied load and sliding distance, respectively. $\Delta V$ is the volume loss characterized according to the following equation:

$$
\Delta V=S L_{1}
$$

where $S$ and $L_{1}$ are the cross-sectional area and length of wear trace, respectively.

\subsection{Characterizations and analyses}

The microstructures of the specimens were measured by X-ray diffraction (XRD, Philips $X^{\prime}$ Pert Pro.) with $\mathrm{Cu} / \mathrm{K}-\alpha 1$ radiation at $40 \mathrm{kV}$ and $50 \mathrm{~mA}$. The chemical structure of $\mathrm{g}-\mathrm{C}_{3} \mathrm{~N}_{4}$ was analyzed by Fourier transform infrared (FT-IR, Nexus 870) spectra. Tribochemical effects were carried out by X-ray photoelectron spectrometer (XPS, ESCALAB 250Xi, Thermo Fisher Scientific) with $\mathrm{Mg} \mathrm{K} \alpha$ radiation source. The thermal stability was explored by thermogravimetric analysis (TGA) on a Netzsch thermal analysis system (STA $449 \mathrm{C}$ ) with temperature range of $30-800{ }^{\circ} \mathrm{C}$ in nitrogen at a rate of $10{ }^{\circ} \mathrm{C} / \mathrm{min}$. The storage modulus of friction materials was evaluated by dynamic mechanical analysis (DMA) on a DMA 242 C analyzer (Netzsch Instruments, Germany) with three-point bending mode heated from $25{ }^{\circ} \mathrm{C}$ to $250{ }^{\circ} \mathrm{C}$ at a rate of $5{ }^{\circ} \mathrm{C} \cdot \mathrm{min}^{-1}$ and frequency of $1 \mathrm{~Hz}$. The morphologies of the transfer films and worn surfaces were inspected with a field-emission scanning electron microscope (FE-SEM, 
Mira 3, Xmu, Tescan) and coated with a thin gold layer to increase the resolution for observation. The 3D tomographies of wear scars were investigated using an optical interferometer (KLA-Tencer, MicroXAM-800) in at least five random areas. The size of $\mathrm{g}-\mathrm{C}_{3} \mathrm{~N}_{4}$ particles was characterized by laser particle diameter analyzer (Mastersizer 3000). The density and hardness of the samples were measured on the Micrometritics AccuPyc 1330 and HS-D TH-210 hardness tester (Beijing Time Technology Co., Ltd., China) on a Shore D scale, respectively.

\section{Results and discussion}

\subsection{Analysis of $\mathrm{g}-\mathrm{C}_{3} \mathrm{~N}_{4}$ microstructure}

FT-IR is an effective method to determine the structures and chemical bonds of the samples. The different functional groups of melamine and $\mathrm{g}-\mathrm{C}_{3} \mathrm{~N}_{4}$ in the $3,700-500 \mathrm{~cm}^{-1}$ region are shown in Fig. 5(a). For the melamine, the double peaks at $3,467 \mathrm{~cm}^{-1}$ and $3,419 \mathrm{~cm}^{-1}$ are related to the antisymmetric stretching vibration of the $-\mathrm{NH}_{2}$ group. The peaks at $1,551 \mathrm{~cm}^{-1}$ and $1,646 \mathrm{~cm}^{-1}$ correspond to the triazine aromatic stretching vibration and $\mathrm{N}-\mathrm{H}$ bending vibration, respectively $[30,31]$. Meanwhile, the peak at $810 \mathrm{~cm}^{-1}$ corresponds to the ring deflection in melamine [31]. In the case of g- $\mathrm{C}_{3} \mathrm{~N}_{4}$, the $\mathrm{C} \equiv \mathrm{N}$ stretching peak at $1,200-1,650 \mathrm{~cm}^{-1}$, triazine unit breathing peak at $810 \mathrm{~cm}^{-1}$, and $\mathrm{N}-\mathrm{H}$ stretching peak at broad band of approximately $3,000 \mathrm{~cm}^{-1}$ were observed [22, 27, 32].

To confirm the formation of pure g- $\mathrm{C}_{3} \mathrm{~N}_{4}$ crystal phases, the samples were analyzed by XRD. As seen in Fig. 5(b), there are two characteristic peaks at $13.0^{\circ}$ and $27.5^{\circ}$ corresponding to (100) and (002) diffraction
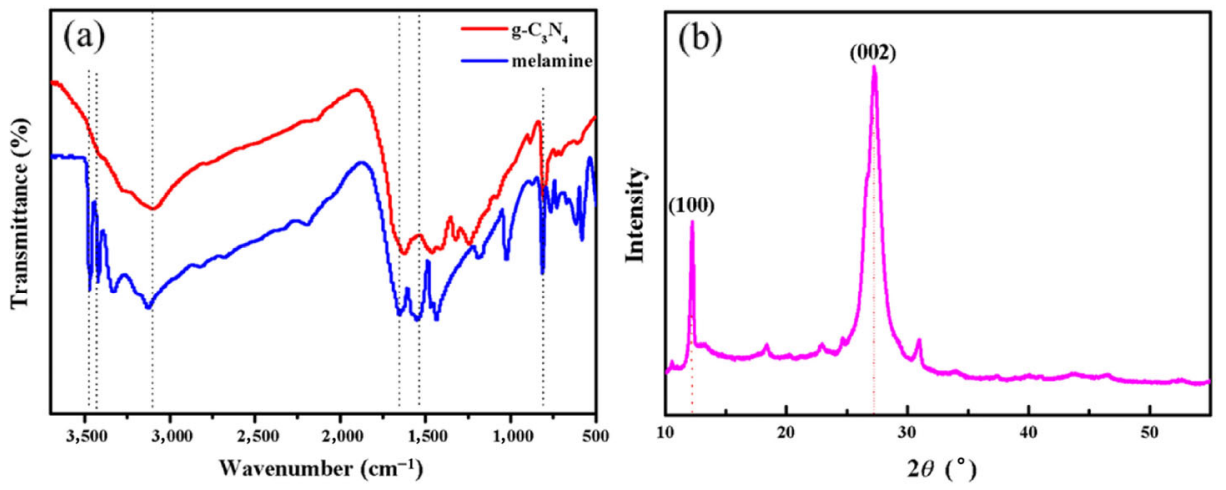

Fig. 5 Structural analysis of $g-\mathrm{C}_{3} \mathrm{~N}_{4}$ powders: (a) FT-IR spectra and (b) XRD pattern. planes, which are associated with interlayer stacking of the conjugated aromatic system [33-35]. Therefore, synthetic $\mathrm{g}-\mathrm{C}_{3} \mathrm{~N}_{4}$ exhibits a typical graphite-like structure. From the above discussion, it is clear that g- $\mathrm{C}_{3} \mathrm{~N}_{4}$ powders were successfully fabricated by directly heating melamine.

\subsection{Thermal performance analysis of composites}

The dynamic thermomechanical properties of PTFE composites were investigated by DMA at $1 \mathrm{~Hz}$ and temperature range of $25-250{ }^{\circ} \mathrm{C}$, as shown in Fig. 6(a). The figure shows that all the composites exhibit similar temperature-dependent viscoelastic properties. Meanwhile, the storage modulus of samples can be improved by incorporating functional fillers. The g- $\mathrm{C}_{3} \mathrm{~N}_{4}$-reinforced composites show higher and improved properties, which indicate that $\mathrm{g}-\mathrm{C}_{3} \mathrm{~N}_{4}$ has the ability to enhance the stiffness and elastic deformation resistance. On the other hand, the interlayer bonding strength of $\mathrm{g}-\mathrm{C}_{3} \mathrm{~N}_{4}$ originating from $\mathrm{H}$-bonds is much higher than that of $\mathrm{MoS}_{2}$ with van der Waals force. Therefore, the unique 2D layer-structure of $\mathrm{g}-\mathrm{C}_{3} \mathrm{~N}_{4}$ exhibits high mechanical properties, as mentioned in reference [36].

Excellent thermal stability has a positive effect in terms of enhanced tribological performance. Figure 6(b) and Table 3 show the influence of layered materials on thermal stability under nitrogen conditions. Data on thermal properties indicate that there is no obvious difference between thermal degradation temperatures of $5 \%$ and $10 \%$ weight loss. However, the char yield value of FM3 at $800{ }^{\circ} \mathrm{C}$ is higher than that of FM1 and FM2, which can be attributed to the higher thermal resistance of $\mathrm{g}-\mathrm{C}_{3} \mathrm{~N}_{4}$. 

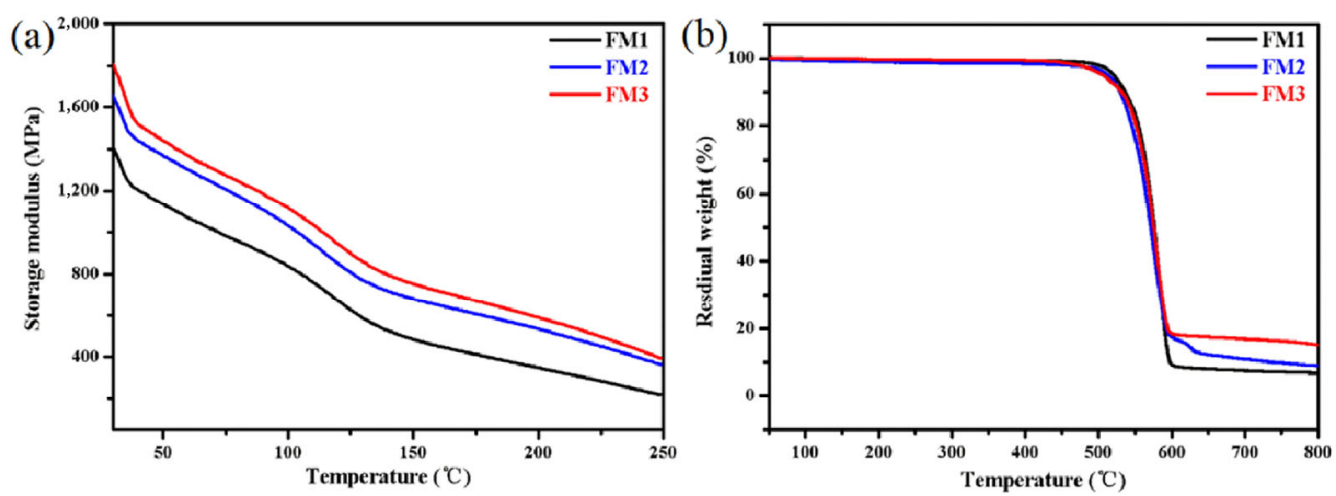

Fig. 6 Thermomechanical and thermal gravimetric analysis of PTFE composites: (a) the temperature-dependent storage modulus, and (b) TGA thermograms.

Table 3 Data of thermal properties of PTFE composites.

\begin{tabular}{cccc}
\hline Composites & $T_{5 \%}\left({ }^{\circ} \mathrm{C}\right)$ & $T_{10 \%}\left({ }^{\circ} \mathrm{C}\right)$ & Char yield $(\%)$ at $800{ }^{\circ} \mathrm{C}$ \\
\hline FM1 & 521.15 & 536.48 & 6.07 \\
FM2 & 513.37 & 529.55 & 8.83 \\
FM3 & 506.68 & 531.66 & 14.32 \\
\hline
\end{tabular}

\subsection{Friction behavior of PTFE composites}

\subsubsection{Effect of sliding speed and normal load on friction coefficient}

Figure 7 presents the friction coefficient of composites with different compositions as a function of different sliding speeds and normal loads. Figure 7(a) shows that the friction coefficient first increases and then decreases with faster sliding speed for FM1 and FM2. However, for sample FM3, this behavior is not evident since the friction coefficients at 0.08 and $0.12 \mathrm{~m} / \mathrm{s}$ show no significant difference. It is obvious that sliding speeds have little influence on the friction coefficient of FM3. The variation in friction coefficient can be explained by the higher interfacial temperature induced by frictional heat in Fig. 7(a). The elevated temperature may cause a tribo-chemical reaction or degradation of polymers, which consumes vast amounts of energy and produces two opposite effects. On the one hand, polymer composites deform easily at high temperature owing to the reduction of elastic modulus. Consequently, the friction coefficient increases with the increase in real contact area. On the other hand, the molecules of polymer surfaces are pressed, drawn, and sheared owing to the mechanical force, and frictional heat leads to the relaxation of molecular chains. Therefore, the shear strength of composites decreases with increased temperature, which results in the decreased friction coefficient [37, 38]. To summarize, when sliding speed is low, deformation of materials is dominant. The reduction in shear strength plays a key role. Figure 7(b) shows that friction coefficient continuously decreases with increasing load for all samples; this variation trend can be explained by following equation $[39,40]$ :

$$
\mu=k N^{n-1}
$$

where $\mu$ and $N$ are the friction coefficient and normal
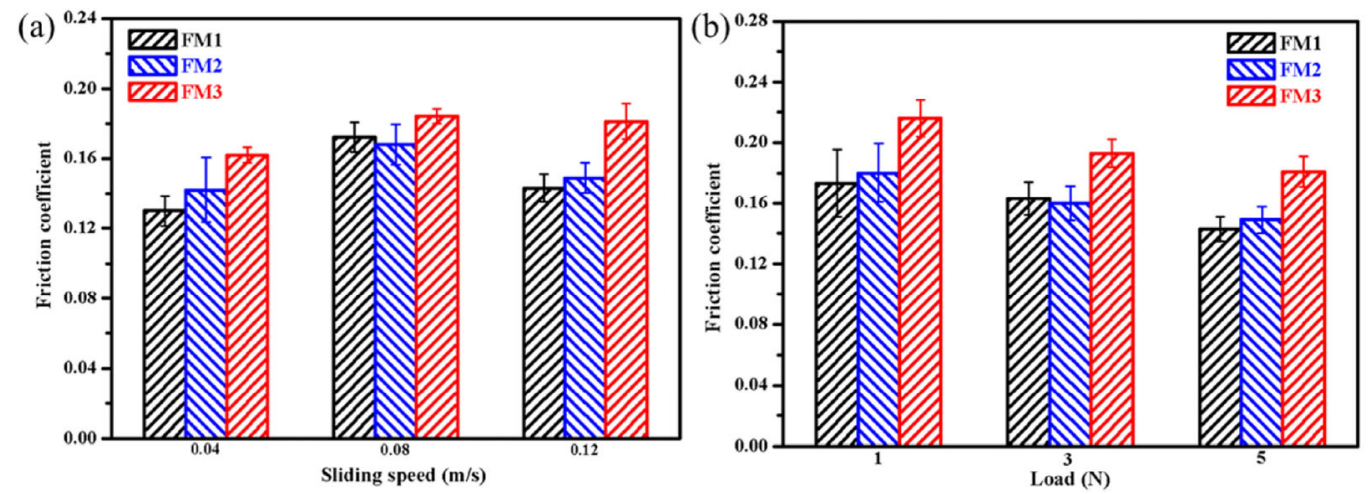

Fig. 7 Variation of friction coefficient with (a) sliding speed at $5 \mathrm{~N}$, and (b) load at $0.12 \mathrm{~m} / \mathrm{s}$. 
load, respectively; $k$ and $n$ are constants $(2 / 3<n<1)$. Accordingly, the friction coefficient is inversely proportional to the load.

\subsubsection{Effect of sliding speed and normal load on specific wear rate}

The changes in specific wear rate of PTFE composites under different sliding speeds and normal loads are plotted in Fig. 8. It is worth noting that the incorporation of $\mathrm{g}-\mathrm{C}_{3} \mathrm{~N}_{4}$ enhances the wear resistance of composites under a wide range of operating conditions. However, the wear of composites increased with addition of $\mathrm{MoS}_{2}$. Similar experimental results were obtained by Zhang et al. [41, 42] and Wang et al. [43], which were attributed to partial oxidation of $\mathrm{MoS}_{2}$ into $\mathrm{MoO}_{3}$, which contributes negatively to the anti-wear properties of composites. Detailed analysis is carried out in the next section. The decrease in wear resistance with increasing speed for all composites (see Fig. 8(a)) can be explained by the fact that the increase in interfacial temperature at higher speed weakens the adhesion between the resin matrix and fillers. The influence of load on the specific wear rate can be seen in Fig. 8(b). The wear of composites gradually decreases with the increase in load. This may be because some large particles and debris are crushed into small particles or flakes on the frictional interface as pressure increased, which prevented direct contact between friction pairs and enhanced wear resistance effectively [44]. It was found that the anti-wear performance of g- $\mathrm{C}_{3} \mathrm{~N}_{4}$-reinforced composites (FM3) is better than composites with traditional fillers.

\subsection{Wear behavior of PTFE composites}

Figure 9 illustrates the 3D morphologies of the wear
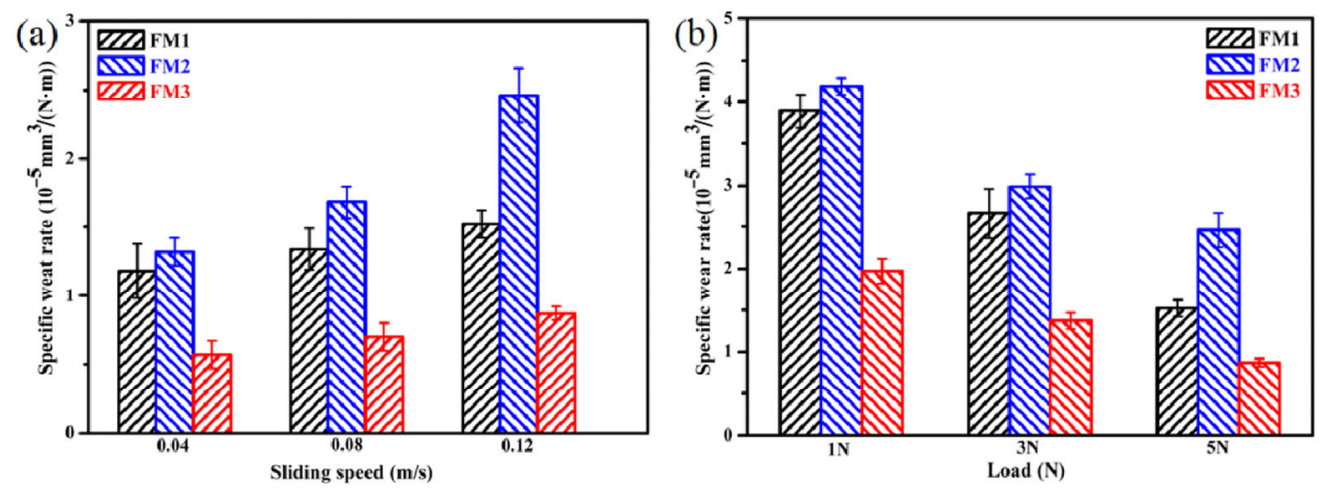

Fig. 8 Variation of specific wear rate with (a) sliding speed at $5 \mathrm{~N}$, and (b) load at $0.12 \mathrm{~m} / \mathrm{s}$.
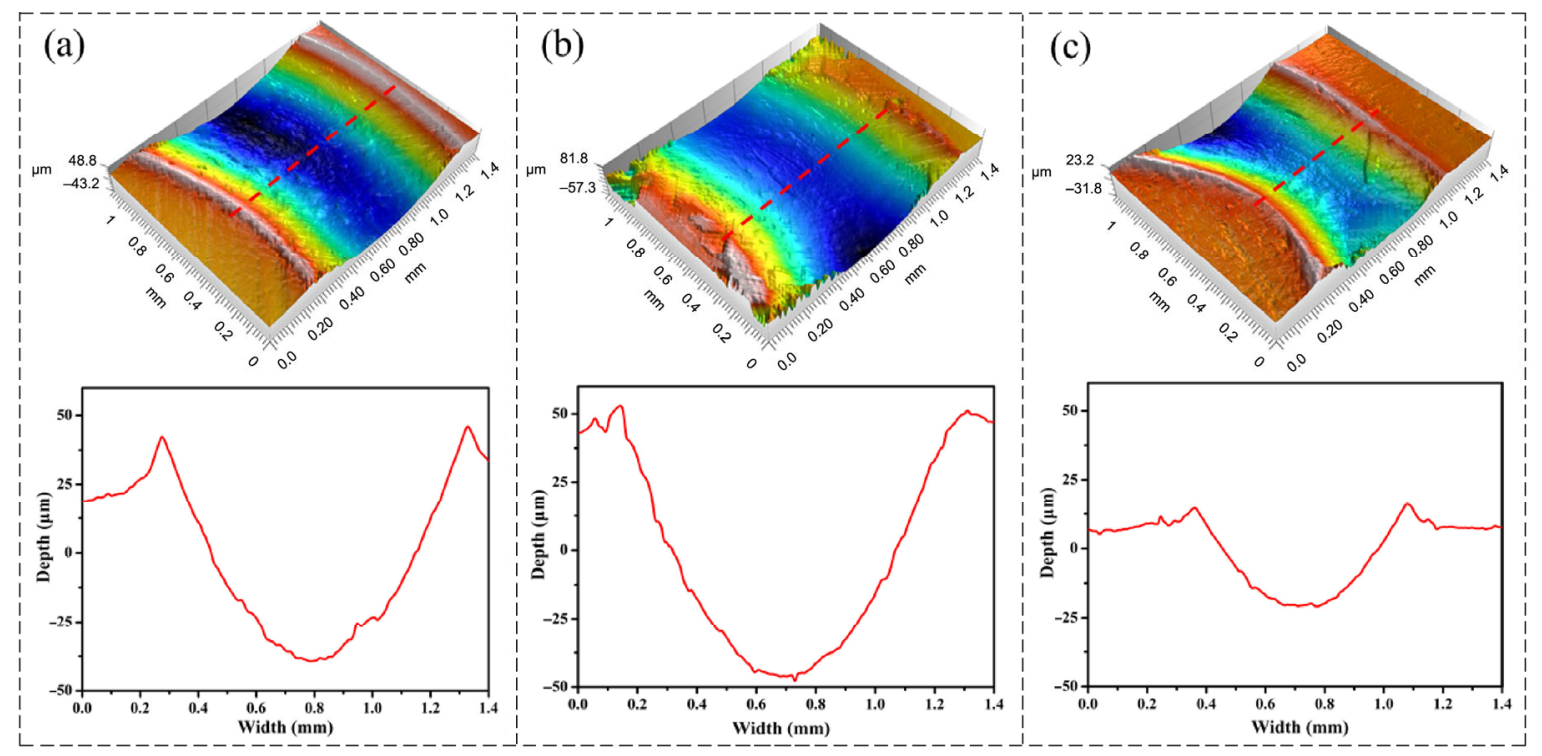

Fig. 9 3D images of grinding marks of worn surfaces: (a) FM1, (b) FM2, and (c) FM3. 
tracks at $5 \mathrm{~N}$ and $0.12 \mathrm{~m} / \mathrm{s}$. All SEM images (Fig. 10) of the worn surface were obtained at the same condition. It is clear that the wear tracks of FM1 and FM2 are much deeper and wider compared with that of FM3, as seen in Fig. 9, which is consistent with wear resistance presented in the preceding Section 3.3. The different anti-wear properties with respect to the different fillers can also be obtained from worn surfaces (see Fig. 10). The severe wear and rough surface can be observed from delaminated worn surfaces, indicating that matrix materials were gradually peeled off (see white circle) owing to thermal softening. Therefore, the main wear mechanism is adhesive and fatigue wear, as shown in the high magnification micrograph (Figs. $10\left(a_{1}\right)$ and $10\left(b_{1}\right)$. In the case of FM2, the specimen is worn because of the partial oxidation of composites. Under same service condition, oxidation reduces the ability to lubricate, resulting in more severe wear damage (see Figs. $10\left(a_{2}\right)$ and $10\left(b_{2}\right)$. Adhesive wear is also the main wear mechanism as shown by the white rectangle in Fig. 10 $\left(b_{2}\right)$. In addition, a lot of wear debris (blue circle) can be seen from the worn surface; these have a detrimental effect on wear resistance and transfer film formation. However, the worn surface

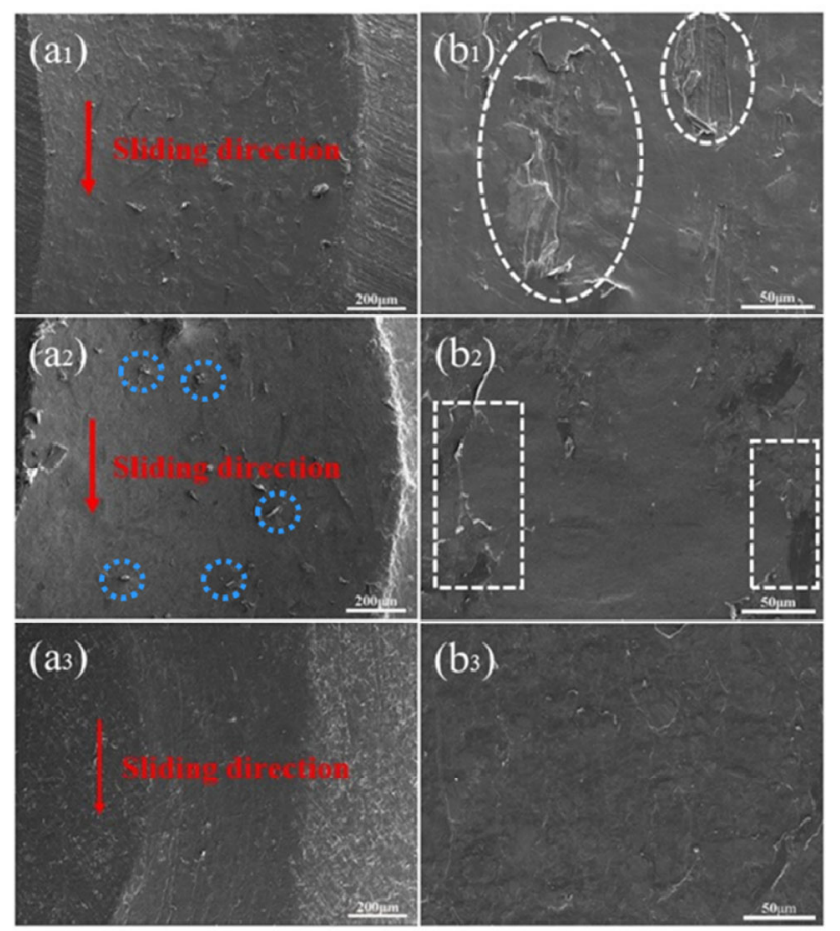

Fig. 10 SEM images of the worn surface of low and high magnification micrographs: FM1 $\left(a_{1}, b_{1}\right)$, FM2 $\left(a_{2}, b_{2}\right)$, and FM3 $\left(a_{3}, b_{3}\right)$. morphology of FM3 is distinctly different. In this case, a much smoother surface is seen, in which the delamination of materials is mitigated significantly. This morphology coincides well with its superior wear resistance. The enhanced anti-wear performance by g- $\mathrm{C}_{3} \mathrm{~N}_{4}$ can be attributed to the high load-bearing capacity and mechanical properties [45].

It is generally believed that transfer films are closely related to the anti-wear performance of polymer/steel tribo-systems [46]. Generally, homogeneous transfer and smooth transfer films are good for high wear resistance owing to the prevention of direct contact between frictional surfaces [47, 48]. Figure 11 shows transfer films formed on counterpart surfaces rubbing against different composites. Figures $11(\mathrm{a})$ and 11(b) show inhomogeneous and rough transfer films of FM1 and FM2, which are consistent with poor wear resistance (Figs. 9(a) and 9(b)). Contrary to the above, uniform, thin, and continuous transfer film is formed from FM3 (see Fig. 11(c)), which indicates the beneficial role of $\mathrm{g}-\mathrm{C}_{3} \mathrm{~N}_{4}$ in helping develop high-quality transfer films that strengthen the wear resistance of PTFE composites.

\subsection{The evolution of tribochemistry and transfer films}

$\mathrm{MoS}_{2}$ is a well-known 2D material, a common solid lubricant with weak van der Waals force between planes. However, $\mathrm{MoS}_{2}$ is easily oxidized into $\mathrm{MoO}_{3}$ under oxygen-rich and elevated temperature conditions, as expressed by Eq. (4). $\mathrm{MoO}_{3}$ has inferior lubricating performance and expands as temperature rises, leading to negative anti-wear effects/properties [49]. Therefore, tribo-oxidation of $\mathrm{MoS}_{2}$ was explored by XPS spectra. The Mo 3d and S 2p XPS spectra on the worn surface of $\mathrm{MoS}_{2}$-reinforced composites at $0.12 \mathrm{~m} / \mathrm{s}$ and $5 \mathrm{~N}$ are shown in Figs. 12(a) and 12(b). In the Mo 3d spectrum, different peaks are exhibited at approximately 233.2 and $229.6 \mathrm{eV}$ for Mo $3 \mathrm{~d}_{3 / 2}$ and $3 \mathrm{~d}_{5 / 2}$ in $\mathrm{MoS}_{2}$ [50]. The peaks at 235.8 and $232.6 \mathrm{eV}$ are assigned to the Mo $3 \mathrm{~d}_{3 / 2}$ and $3 \mathrm{~d}_{5 / 2}$ in $\mathrm{MoO}_{3}$. Figure 12(b) shows a doublet at 162 and $163.2 \mathrm{eV}$ corresponding to the $S 2 \mathrm{p}_{3 / 2}$ and $2 \mathrm{p}_{1 / 2}$ peaks of $\mathrm{S}^{2-}$ in $\mathrm{MoS}_{2}$. In addition, the peak at $168.3 \mathrm{eV}$ is consistent with $\mathrm{SO}_{4}{ }^{2-}$ [51, 52]. According to above analysis, partial oxidation of $\mathrm{MoS}_{2}$ into $\mathrm{MoO}_{3}$ occurred, which leads to poor wear resistance. 


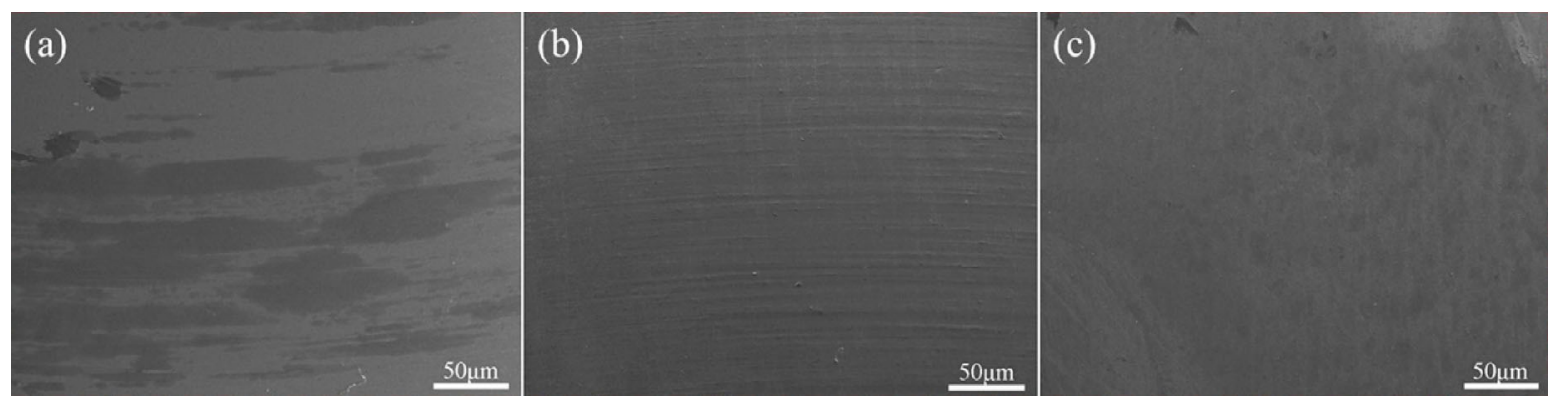

Fig. 11 Morphologies of the transfer films of counterparts: (a) FM1, (b) FM2, and (c) FM3.
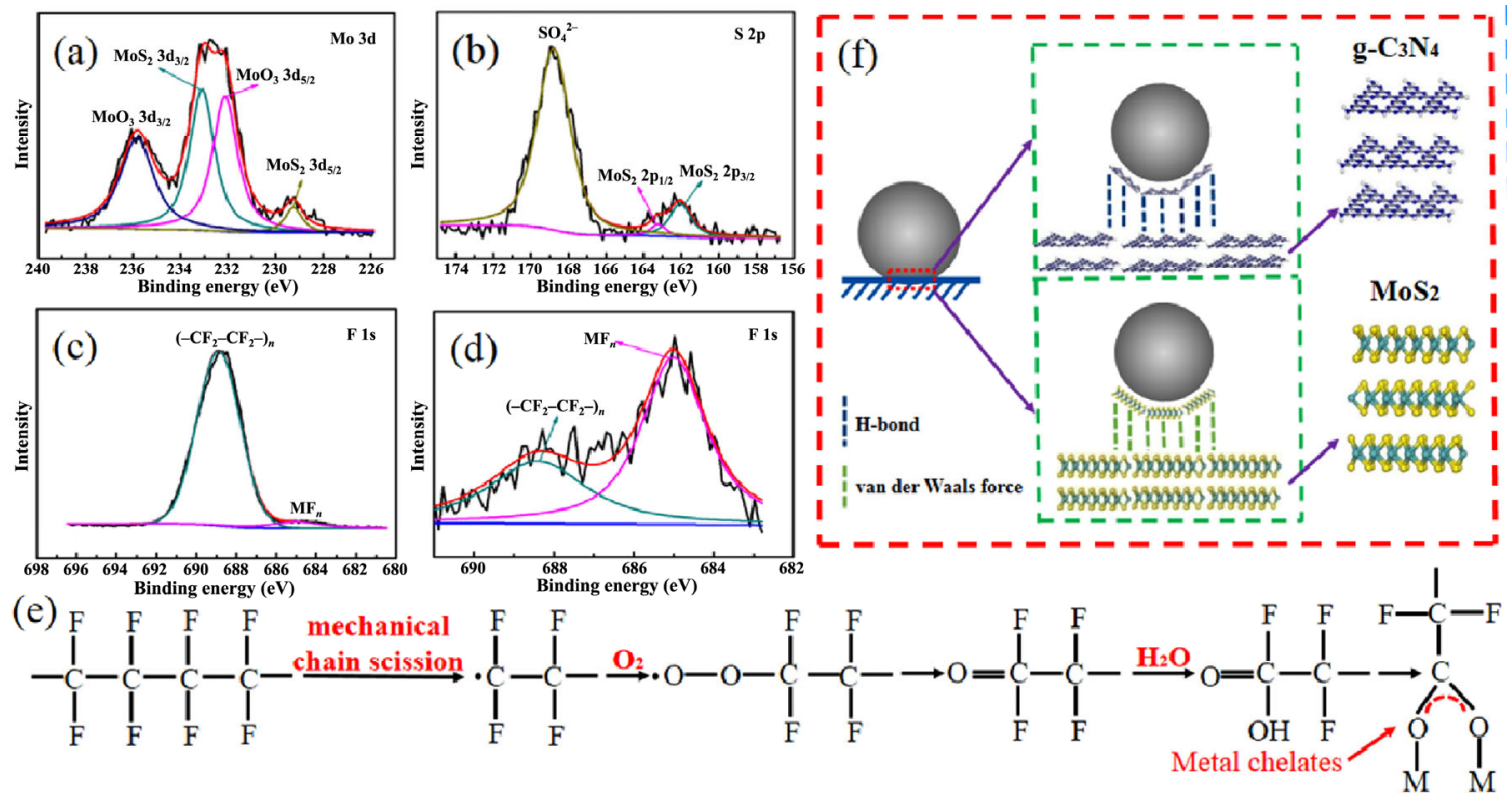

Fig. 12 XPS spectra of (a) Mo 3d, (b) S 2p, (c) F 1s on the worn surface, and (d) F 1s on metallic counterpart. The evolution of (e) tribochemistry and (f) transfer films.

$$
\mathrm{MoS}_{2}+\mathrm{O}_{2} \rightarrow \mathrm{MoO}_{3}+\mathrm{SO}_{2}
$$

Figures 12(c) and 12(d) show the F 1s spectra of composites and counterparts, respectively. It can be seen that metal fluorides were developed with the peak at approximately $685 \mathrm{eV}$ [53]. When the PTFE composites rubbed against the metal counterparts, transfer films were formed owing to the easy shear of PTFE lamellae. Tribochemical reaction, mechanical compression, tension, and shear play a crucial role in transfer film formation. According to Refs. [54, 55], Figs. 12(e) and 12(f) show the evolution of tribochemistry and transfer films, respectively. During sliding, chain breakdown of the -C-C- or -C-F- backbone bond of PTFE can occur. Then, carboxylic acid end-groups chelate to the metal, developing robust transfer films. Extremely complex tribochemical reactions take place on the frictional surfaces of polymer and metal, which form transfer films that reduce the wear rate of materials, often drastically.

\section{Conclusions}

In this paper, the effect of different layered materials $\left(\mathrm{MoS}_{2}\right.$ and $\left.\mathrm{g}-\mathrm{C}_{3} \mathrm{~N}_{4}\right)$ on thermal stability and thermomechanical properties were investigated. Meanwhile, the tribological properties of PTFE composites were also investigated at different sliding speeds and normal loads. According to the results, the following main conclusions can be drawn:

1. The two types of lamellar materials have a positive effect on thermal stability and thermomechanical properties. The char yield value and storage modulus can be significantly increased by incorporating g- $\mathrm{C}_{3} \mathrm{~N}_{4}$. 
2. Tribological properties of composites are improved by modification with $\mathrm{g}-\mathrm{C}_{3} \mathrm{~N}_{4}$, which has enormous potential as a functional filler. At selected load and speed, g- $\mathrm{C}_{3} \mathrm{~N}_{4}$-reinforced PTFE composites greatly enhance wear resistance.

3. The excellent thermal stability and tribological and thermomechanical properties of PTFE composites with the addition of $\mathrm{g}-\mathrm{C}_{3} \mathrm{~N}_{4}$ are highly dependent on the bonding strength of $\mathrm{H}$-bonds, which is stronger than the van der Waals force of $\mathrm{MoS}_{2}$.

\section{Acknowledgements}

The authors would like to thank the financial support from National Basic Research Program of China (973 Program, Grant No. 2015CB057502), the Youth Innovation Promotion Association of Chinese Academy of Sciences (Grant No. 2018457), and National Key Research and Development Plan (Grant No. 2016YFF0101000). This research was also partially supported by the Key Research Program of Frontier Science, Chinese Academy of Sciences (Grant No. QYZDJ-SSW-SLH056) and National Natural Science Foundation of China (Grant No. 51673205).

Open Access This article is licensed under a Creative Commons Attribution 4.0 International License, which permits use, sharing, adaptation, distribution and reproduction in any medium or format, as long as you give appropriate credit to the original author(s) and the source, provide a link to the Creative Commons licence, and indicate if changes were made.

The images or other third party material in this article are included in the article's Creative Commons licence, unless indicated otherwise in a credit line to the material. If material is not included in the article's Creative Commons licence and your intended use is not permitted by statutory regulation or exceeds the permitted use, you will need to obtain permission directly from the copyright holder.

To view a copy of this licence, visit http://creativecommons.org/licenses/by/4.0/.

\section{References}

[1] Zhao G, Hussainova I, Antonov M, Wang Q, Wang T. Friction and wear of fiber reinforced polyimide composites.
Wear 301: 122-129 (2013)

[2] Myshkin N, Kovalev A. Adhesion and surface forces in polymer tribology - A review. Friction 6: 143-55 (2018)

[3] Wang Z, Ni J, Gao D. Combined effect of the use of carbon fiber and seawater and the molecular structure on the tribological behavior of polymer materials. Friction 6: 183-194 (2018)

[4] Shi Y, Feng X, Wang H, Liu C, Lu X. Effects of filler crystal structure and shape on the tribological properties of PTFE composites. Tribol Int 40: 1195-1203 (2007)

[5] Burris D L, Sawyer W G. Improved wear resistance in alumina-PTFE nanocomposites with irregular shaped nanoparticles. Wear 260: 915-918 (2006)

[6] Khedkar J, Negulescu I, Meletis E I. Sliding wear behavior of PTFE composites. Wear 252: 361-369 (2002)

[7] Shi Y, Feng X, Wang H, Lu X. The effect of surface modification on the friction and wear behavior of carbon nanofiber-filled PTFE composites. Wear 264: 934-939 (2008)

[8] Bahadur S, Polineni V. Tribological studies of glass fabricreinforced polyamide composites filled with $\mathrm{CuO}$ and PTFE. Wear 200: 95-104 (1996)

[9] Sawyer W G, Freudenberg K D, Bhimaraj P, Schadler L S. A study on the friction and wear behavior of PTFE filled with alumina nanoparticles. Wear 254: 573-580 (2003)

[10] Wang Q, Wang Y, Wang H, Fan N, Wang M, Liu H, et al. Comparative study of the effects of nano-sized and micro-sized $\mathrm{CF}$ and PTFE on the thermal and tribological properties of PEEK composites. Polym Adv Technol 29: 896-905 (2018)

[11] Burris D L, Sawyer W G. Improved wear resistance in alumina-PTFE nanocomposites with irregular shaped nanoparticles. Wear 260: 915-918 (2006)

[12] Conte M, Igartua A. Study of PTFE composites tribological behavior. Wear 296: 568-574 (2012)

[13] Li F, Hu K-A, Li J-L, Zhao B-Y. The friction and wear characteristics of nanometer $\mathrm{ZnO}$ filled polytetrafluoroethylene. Wear 249: 877-882 (2001)

[14] Ye J, Khare H, Burris D. Transfer film evolution and its role in promoting ultra-low wear of a PTFE nanocomposite. Wear 297: 1095-1102 (2013)

[15] Fan Y, Ding Q J, Yao Z Y. Properties of potassium titanate whisker reinforced polytetrafluoroethylene-based friction materials of ultrasonic motors. J Appl Polym Sci 125: 3313-3317 (2012)

[16] Song F, Wang Q, Wang T. Effects of glass fiber and molybdenum disulfide on tribological behaviors and PV limit of chopped carbon fiber reinforced Polytetrafluoroethylene composites. Tribol Int 104: 392-401 (2016) 
[17] Qu J, Zhang Y, Tian X, Li J. Wear behavior of filled polymers for ultrasonic motor in vacuum environments. Wear 322: 108-116 (2015)

[18] Spear J C, Ewers B W, Batteas J D. 2D-nanomaterials for controlling friction and wear at interfaces. Nano Today 10: 301-314 (2015)

[19] Leven I, Maaravi T, Azuri I, Kronik L, Hod O. Interlayer Potential for Graphene/h-BN Heterostructures. J Chem Theory Comput 12: 2896-2905 (2016)

[20] Xiao H, Liu S. 2D nanomaterials as lubricant additive: A review. Mater Design 135: 319-332 (2017)

[21] Jiang W, Luo W, Wang J, Zhang M, Zhu Y. Enhancement of catalytic activity and oxidative ability for graphitic carbon nitride. J Photoch Photobio C 28: 87-115 (2016)

[22] Zhang L, Qi H, Li G, Wang D, Wang T, Wang Q, Zhang G. Significantly enhanced wear resistance of PEEK by simply filling with modified graphitic carbon nitride. Mater Design 129: 192-200 (2017)

[23] Groenewolt M, Antonietti M. Synthesis of $\mathrm{g}-\mathrm{C}_{3} \mathrm{~N}_{4}$ nanoparticles in mesoporous silica host matrices. Adv Mater 17: 1789-1792 (2005)

[24] Niu P, Zhang L, Liu G, Cheng H M. Graphene-like carbon nitride nanosheets for improved photocatalytic activities. Adv Funct Mater 22: 4763-4770 (2012)

[25] Cai P, Wang T, Wang Q. Formulation optimization of friction material with golden section approach. Tribol T 59: 28-32 (2015)

[26] Li S, Shao M, Duan C, Yan Y, Wang Q, Wang T, Wang T, Zhang $\mathrm{X}$. Tribological behavior prediction of friction materials for ultrasonic motors using Monte Carlo-based artificial neural network. J Appl Polym Sci 47157 (2018)

[27] Zhu L, Wang Y, Hu F, Song H. Structural and friction characteristics of $\mathrm{g}_{-} \mathrm{C}_{3} \mathrm{~N}_{4} / \mathrm{PVDF}$ composites. Appl Surf Sci 345: 349-354 (2015)

[28] Pettarin V, Churruca M J, Felhös D, Karger-Kocsis J, Frontini P M. Changes in tribological performance of high molecular weight high density polyethylene induced by the addition of molybdenum disulphide particles. Wear 269: 31-45 (2010)

[29] Yan S, Li Z, Zou Z. Photodegradation performance of g-C3N4 fabricated by directly heating melamine. Langmuir $\mathbf{2 5}$ : 10397-10401 (2009)

[30] Wang H, Kojtari A, Xu X, Ji H-F. Self-Assembled Microwires of Terephthalic Acid and Melamine. Crystals 7: 236 (2017)

[31] Bowden P R, Leonard P W, Lichthardt J P, Tappan B C, Ramos K J. Energetic salt of trinitrophloroglucinol and melamine. In AIP Conference Proceedings, 2017, 040014.
[32] Zhu L, You L, Shi Z, Song H, Li S. An investigation on the graphitic carbon nitride reinforced polyimide composite and evaluation of its tribological properties. J Appl Polym Sci 134: 45403 (2017)

[33] Yng J, Zhang H, Chen B, Tang H, Li C, Zhang Z. Fabrication of the $g-\mathrm{C}_{3} \mathrm{~N}_{4} / \mathrm{Cu}$ nanocomposite and its potential for lubrication applications. $R S C A d v$ 5: 64254-60 (2015)

[34] Ge L, Han C. Synthesis of MWNTs/g- $\mathrm{C}_{3} \mathrm{~N}_{4}$ composite photocatalysts with efficient visible light photocatalytic hydrogen evolution activity. Appl Catal B: Environ 117: 268-274 (2012)

[35] Liu W, Wang M, Xu C, Chen S. Facile synthesis of $g-\mathrm{C}_{3} \mathrm{~N}_{4} /$ $\mathrm{ZnO}$ composite with enhanced visible light photooxidation and photoreduction properties. Chem Eng J 209: 386-393 (2012)

[36] Wang X L, Fang W Q, Wang H F, Zhang H, Zhao H, Yao Y, et al. Surface hydrogen bonding can enhance photocatalytic $\mathrm{H}_{2}$ evolution efficiency. J Mater Chem A 1: 14089-14096 (2013)

[37] Unal H, Mimaroglu A, Kadioglu U, Ekiz H. Sliding friction and wear behaviour of polytetrafluoroethylene and its composites under dry conditions. Mater Design 25 : 239-245 (2004)

[38] Cai P, Li Z, Wang T, Wang Q. Effect of aspect ratios of aramid fiber on mechanical and tribological behaviors of friction materials. Tribol Int 92: 109-116 (2015)

[39] Stuart B H. Surface plasticisation of poly(ether ether ketone) by chloroform. Polym Test 16: 49-57 (1997)

[40] Cai P, Wang Y, Wang T, Wang Q. Improving tribological behaviors of friction material by mullite. Tribol Int 93 : 282-288 (2016)

[41] Su F-H, Zhang Z-Z, Guo F, Wang K, Liu W-M. Effects of solid lubricants on friction and wear properties of Nomex fabric composites. Mater Sci Eng A 424: 333-339 (2006)

[42] Zhang H-J, Zhang Z-Z, Guo F. Studies of the Influence of Graphite and $\mathrm{MoS}_{2}$ on the Tribological Behaviors of Hybrid PTFE/Nomex Fabric Composite. Tribol T 54: 417-423 (2011)

[43] Li X, Gao Y, Xing J, Wang Y, Fang L. Wear reduction mechanism of graphite and $\mathrm{MoS}_{2}$ in epoxy composites. Wear 257: 279-283 (2004)

[44] Zhao G, Wang T, Wang Q. Surface modification of carbon fiber and its effects on the mechanical and tribological properties of the polyurethane composites. Polym Compos 32: 1726-1733 (2011)

[45] Duan C, Yuan D, Yang Z, Li S, Tao L, Wang Q, Wang T. High wear-resistant performance of thermosetting polyimide reinforced by graphitic carbon nitride $\left(\mathrm{g}-\mathrm{C}_{3} \mathrm{~N}_{4}\right)$ under high temperature. Compos Part A: Appl Sci Manuf 113: 200-208 (2018) 
[46] Wang Q, Wang H, Fan N, Wang Y, Yan F. Combined effect of fibers and PTFE nanoparticles on improving the fretting wear resistance of UHMWPE-matrix composites. Polym Adv Technol 27: 642-650 (2016)

[47] Eriksson M, Bergman F, Jacobson S. On the nature of tribological contact in automotive brakes. Wear 252: 26-36 (2002)

[48] Qi H, Li G, Zhang G, Wang T, Wang Q. Impact of counterpart materials and nanoparticles on the transfer film structures of polyimide composites. Mater Design 109: 367-377 (2016)

[49] Zhang H-J, Zhang Z-Z, Guo F. Studies of the influence of graphite and $\mathrm{MoS}_{2}$ on the tribological behaviors of hybrid PTFE/Nomex fabric composite. Tribol T 54: 417-423 (2011)

[50] Turner N, Single A. Determination of peak positions and areas from wide-scan XPS spectra. Surf Interface Anal 15:

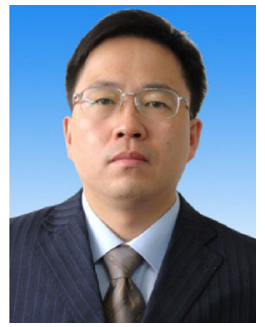

Qihua WANG. He graduated from North Western Polytechnical University with a bachelor's degree in engineering in July 1990 and a Ph.D. degree in Lanzhou Institute of Chemical Physics, Chinese Academy of Sciences in July 1998. In 2004, he worked as a senior visiting scholar at the Department of Chemistry at the University of Houston, USA. He is

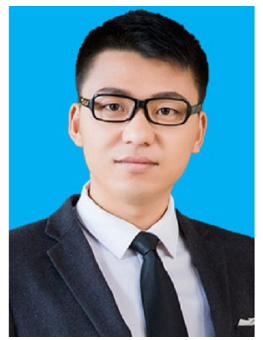

Song LI. He is a Ph.D. candidate in the Lanzhou Institute of Chemical Physics, Chinese Academy of Sciences, University of Chinese Academy

\section{$215-222(1990)$}

[51] Cai P, Wang T, Wang Q. Effect of several solid lubricants on the mechanical and tribological properties of phenolic resinbased composites. Polym Compos 36: 2203-2211 (2015)

[52] Wong K, Lu X, Cotter J, Eadie D, Wong P, Mitchell K. Surface and friction characterization of $\mathrm{MoS}_{2}$ and $\mathrm{WS}_{2}$ third body thin films under simulated wheel/rail rolling-sliding contact. Wear 264: 526-534 (2008)

[53] Gao J, Mao S, Liu J, Feng D. Tribochemical effects of some polymers/stainless steel. Wear 212: 238-243 (1997)

[54] Jintang G. Tribochemical effects in formation of polymer transfer film. Wear 245: 100-106 (2000)

[55] Harris K L, Pitenis A A, Sawyer W G, Krick B A, Blackman G S, Kasprzak D J, Junk C P. PTFE tribology and the role of mechanochemistry in the development of protective surface films. Macromolecules 48: 3739-3745 (2015)

currently a researcher and doctoral supervisor. He is the winner of the National Outstanding Youth Fund and his current research interests include composite tribology, space environmental material failure behavior and mechanism, and lubrication materials and sealing techniques under severe conditions. He has published more than 100 papers in important journals at domestic and international. As a group leader, he has under taken more than 20 research projects.

of Sciences. His research is focused on the tribological problems in ultrasonic motors, and the development of polymer-based friction material. 